\title{
Quantitative methods of urban morphology in urban design and environmental psychology
}

\author{
Irem Erin', Giovanni Fusco ${ }^{2}$, Ebru Cubukcu', Alessandro Araldi ${ }^{2}$ \\ ${ }^{1}$ City and Regional Planning Department. Dokuz Eylul University. Turkey \\ ${ }^{2}$ Université Côte d'Azur. France
}

E-mail: irem.erin@deu.edu.tr, giovanni.fusco@unice.fr, ebru.cubukcu@deu.edu.tr, alessandro. araldi@unice.fr

\begin{abstract}
Urban morphology investigates the physical form of the city and the historical processes behind its formation. Together with the qualitative analysis, the founding fathers of urban morphology also proposed quantitative measures of urban form. Urban morphologists have traditionally resisted computer-based geoprocessing of urban form and their calculations were mainly carried out manually. Thanks to technological developments, the number of quantitative studies in urban morphology has increased and fully integrated geoprocessing. More sophisticated computer-aided analyses enhance the potential applications in urban design and in environmental psychology research. Space Syntax (Hillier 1998) and Multiple Centrality Assessment (Porta et al. 2006) are configurational, multi-scale approaches to the analysis of the urban street networks, but miss the interplay between streets, building and parcels composing urban fabric. Space Matrix (Berghauser Pont and Haupt 2010) and, more recently, Multiple Fabric Assessment (Araldi and Fusco 2017) are geoprocessing quantitative approaches to the analysis of urban fabric morphology. This study has two aims; (1) classify quantitative urban morphology methods and (2) discuss how these methods could be applied in urban design and environmental psychology. First, we will present the evolution of these methods along with the theories in urban morphology from qualitative to quantitative approaches. Then, we will discuss how these methods could be combined and used in two related areas: urban design and environmental psychology.
\end{abstract}

Keywords: Urban morphology, quantitative methods, geoprocessing, urban design, environmental psychology.

\section{Introduction}

Urban morphologists are rooted from diverse disciplines such as geography, architecture, urban planning, history and sociology. As "urban morphology" helps to understand the creation and the transformation of urban form, it is particularly important for urban design. At the same time, humans are the primary agency of cities and settlements; their perception, cognition, behaviour and preferences have a direct relationship with urban form. Environmental psychologists have been studying the interrelation between "urban form" and "human perception, cognition, behaviour and preferences" since 1960s. Given that, various measures of "urban form" were used vastly in research and practices of urban design and environmental psychology. However, urban morphology is experiencing important developments thanks to the implementation of new geoprocessing approaches to the quantitative analysis of urban form. The use of these new urban morphology quantitative approaches are comparatively minor in urban design and especially in environmental psychology. Discussing how 
quantitative and geoprocessing-based urban morphology could be integrated in urban design and environmental psychology research and practice is the main concern of this study. To pave the way, this study first presents the evolution of urban morphology theories and approaches form qualitative to quantitative methods in terms of their goals, morphological objects and scales. In the second part, it discusses how urban morphology methods can be utilized in urban design and environmental psychology research and practice.

\section{Urban morphology: from quantitative methods to geoprocessing}

The origin of urban morphology can be traced back to the works of German urban geographers of the late XIX and the early XX century. The works by Fritz, Schlüter, Ratzel and later Hassinger, Geisler, Bobek and Louis laid the foundations of an accurate historical and geographical analysis of urban forms of the European cities, taking into consideration street layouts, building styles and arrangements, function locations and centralities (Hofmeister, 2004). New thematic maps were proposed where colours and symbols represented the main characteristics of the form elements, allowing for the first time a basic quantification of morphological characteristics over the geographic space.

The classical urban morphology schools after WW2 in Britain, Italy and France developed new original concepts in the study of urban form. For example, Conzen (1960) further developed Herbert Louis' concept of urban fringe-belt and analysed the town plan based on three different components of the plan: streets and their arrangements in a street system, plots and their aggregation in street blocks and building arrangements within the street blocks. Conzen also proposed the concept of "morphological region" which can be defined as a clearly recognizable area within the urban space relying on qualitative measures (such as the expert's interpretation of dimensions of parcels and buildings, connections of the streets). Later, Whitehand (2009), as well as Larkham and Morton (2011) highlighted the need of more clarity in the identification and delimitation of morphological regions.

In Italy, Muratori (1959) and later Caniggia and Maffei (1979) also developed new concepts like the building type and the urban tissue which needed careful measurements of building characteristics and aggregation of buildings within plots and street networks in order to be identified and characterized. But both the British and the Italian school remained relatively qualitative in their use of the measured features of urban form.

Although urban morphology in its early stage did not feel the need to engage in the algorithms of spatial analysis, the endeavour of the French school of urban morphology gives rise to the systematization of quantitative measurements of urban forms. Yet, quantitative urban geographers (like Haggett et al., 1977) were more interested in questions of land use and location of urban functions than on the analysis of urban form at the fine grain of urban fabrics. It is no surprise that detailed measurements were often carried out on limited case studies (paradigmatic examples of urban fabrics, small towns, city-centres). The Versailles school (for example Castex et al., 1980), and even more the Parisian school (Borie et al., 2006) proposed a systematic way to qualify and quantify spatial relations among form elements. Buildings, plots and streets are thus characterized by dimensional, geometrical (i.e. angular) and topological relations that define an urban fabric much more than building styles and functional occupation. Site characteristics (topography, hydrography) and their relations to urban fabrics can also be analysed, as already shown by the German forerunners of urban morphology. Such analytical approaches can be applied via the manuals developed by Borie and Denieul (1984) and Allain (2004). Quantitative approaches developed between 60s and 80 s relied heavily on manual measurement and interpretation of calculus. The only remarkable exception in this overall picture was the research carried out at the Centre for the Land Use and Build Form Studies (LUBFS) at the University of Cambridge. Martin et al. (1972) first introduced the use of computeraided mathematical models to analyse the morphological characteristics of the built 
environment. Kruger (1977) and Steadman (1983) also introduced the use of graph theory to analyse and characterize both urban fabrics and three-dimensional buildings. For the first time, quantitative approaches in urban morphology became geoprocessing methods that were being developed by spatial analysis. From this moment on, we can distinguish two broad directions of research within quantitative urban morphology: (1) configurational analysis and (2) geoprocessing and spatial analysis (often within GIS environments).

The common goal of configurational analysis is to quantify the capacity of network configuration (street segments, visual axes, etc.) to structure movement and encounter patterns within urban space. The analysis is based on the calculus of spatial properties of form elements that derive from the spatial relations that they establish with all other form elements within the urban space (or within a shorter radius of analysis). Hillier and Hanson (1984) and Hillier (1998) develop a coherent theoretical framework and several methodological approaches to configurational analysis called Space Syntax. The object of the analysis is the urban grid, made up of all open public spaces available for pedestrian movement in the city. The urban grid can be conceived either as a network of interlinked visual axis or as a network of adjacent convex spaces. Once these networks are modelled as graphs, graph-theoretical algorithms can quantify the configurational properties of each network element. More particularly, axial analyses use a dual graph of the axial network, where axes are represented by nodes and intersections by arcs.

Developing on Freeman's structural sociology (Freeman, 1979) and on the traditional graph representation of street networks proposed by transportation models, Multiple Centrality Assessment (Porta et al., 2006a) uses a primal graph of the street network to analyse configurational properties of street segments within urban space. By introducing buildings served by the network, Urban Network Analysis (Sevtsuk and Mekonnen, 2012) adds the influence of the building fabric in producing potential movement on the street network. Besides Axial Space Syntax and Multiple Centrality Assessment; Angular Analysis (Turner, 2000), Continuity Analysis (Figueiredo and Amorim, 2005), Intersection Continuity Negotiation (Porta et al., 2006b), Mark Point Parameter Analysis (Cutini et al., 2004), etc. also aim at quantifying the properties of network configuration. Fusco and Tirico (2016) offer a systematic overview of the configurational approaches.

In brief, configurational analysis has profoundly renewed quantitative approaches to urban form, departing considerably from the analysis of urban fabrics proposed by the schools of urban morphology. In so doing, it focused on the network component of the morphological system and on the potential flows and interaction patterns that they allow. In another direction, the development of GIS platforms and of spatial analysis algorithms has also allowed the geoprocessing of urban fabric analysis. Here, the spatial relations between contiguous, directly connected, closely related elements prevail over the configurational calculus of relations established between all form elements. Using this approach, Urhahn and Bobic (1994) categorized the city neighbourhoods based on a quantitative and qualitative description of buildings, land-use, mobility infrastructure, etc.

Other authors use quantitative analyses to better explore the descriptive dimensions of selected components of the urban fabric. Marshall (2005) define street typologies and street fabric typologies via new quantitative descriptors of the spatial assembling and complexity of streets. Berghauser-Pont and Haupt (2010) identify typo-morphologies of urban blocks in contemporary cities by cross-analysing different dimensions of urban density (built intensity, compactness, open space ratio and building height) in street blocks. Fusco (2016) uses Bayesian clustering in order to identify administrative units sharing a same subset of common features of urban form (including some key configurational parameters) and functions. Frankhauser (1994) and Thomas et al. (2007) use fractal analysis to investigate the distribution of built up elements in urban form.

As several authors have already pointed out, the precise objectives of the analysis of urban 
form inevitably influence the selection of descriptors of urban fabric, as well as the basic units of the analysis. As far as base spatial units are concerned, grid (Long and Kergomard, 2005), urban blocks (Puissant, 2010; Gil et al., 2012; Bernabé et al., 2013; Giannopoulou et al., 2014) and administrative boundaries (from Urhahn and Bobic, 1994 to Fusco, 2016), are the most common options.

Yet, for urban designers and environmental psychologists the urban fabric should be analysed at a micro-scale that makes sense to city users. To do that, the interplay between buildings, parcels, streets and site needs to be understood. The scientific community is thus increasingly proposing new geoprocessing approaches and different degrees of computer-aided automation to analyse the multidimensional character of urban fabric. Hamaina et al. (2014) were the first to propose a partition of urban space based on a generalized Thiessen polygon starting from the built-up footprint. Araldi and Fusco (2017) use generalized Thiessen polygons around street segments, with visibility thresholds to define a new basic unit from the pedestrian point of view: the proximity band around a street segment. Contrary to the tradition of urban morphologists, these authors focused on the pedestrian point of view. People perceive the urban fabric on both sides of the street, not the elements within the four sides of a block. This difference in basic unit definition increases the potential use of urban morphology in urban design research and practice.

In brief, these considerations on basic unit definition take us back to the goals of the analysis of urban fabric. When the morphological processes are considered, parcel and street block subdivisions seem particularly advantageous. The many analyses focused on micro-climatic or energy-consumption issues (like Long and Kergomard, 2005; Puissant, 2010; Bernabé et al., 2013) find street-blocks as practical units of analysis or use a superimposed grid. With the goal of identifying typologies of urban forms perceived by pedestrians, Araldi and Fusco (2017) use proximity bands around street segments: this approach could be particularly appropriate in the study of urban phenomena related to human perception, like retail activity, crime, residential satisfaction, etc.

\section{Potential Implications of Urban Morphology in Urban Design}

Madanipour (1997) defines "urban design" as "the multi-disciplinary activity of shaping and managing urban environments" (p.22). Considering the fact that "urban morphology" aims to understand the process of shaping urban environment, the two disciplines are clearly related. Likewise, the pioneers of urban design (Alexander, 1977; Kostof, 1992) discussed urban design issues via "urban patterns". In other words, urban design is about "creating patterns" and urban morphology is about understanding and evaluating these patterns (Marshall and Caliskan, 2011). Given that, a number of researchers state that urban morphology should make a significant contribution to urban design both in theory and in practice (Whitehand, 2005). Yet, many others criticized the weak communication between the two disciplines. For example McCormack (2013) states that "although urban morphology is fundamentally concerned with the what, how and why of the constitution of the urban fabric, there is little or no knowledge of this essential reality among practitioners of urbanism" (p.45).

The integration of urban morphology with urban design can be discussed in three parts: theories, research tools and applied values. First, urban morphology initiates various theories of urban design. The issues discussed in Urban Design Readers edited by Carmona and Tiesdell (2007) and by Larice and Macdonald (2013) refer to urban morphology quite often. For example, Trancik's (1986) figure-ground analysis and concept of lost space relates directly to urban morphology. The possibilities of using grid in planning (Martin, 1972), the decline of functionalism and the rise of interest in precedent, context, and typology (Kelbaugh, 2002) could not be discussed without urban morphology.

Secondly, urban morphology is used as a research tool in urban design. For example, 
Moudon (2013) labels typology-morphology and space-morphology studies as two of nine research areas in urban design. Urban morphology can be utilized as a tool to understand the existing settlements via decomposing the city components (Oliveira, 2015; Oliveira, 2013) and classifying the existing patterns (Berghauser Pont and Haupt 2010; Urhahn and Bobic, 1994; Gil et al., 2012; Bernabé et al., 2013; Araldi and Fusco, 2017; Fusco and Araldi, 2017), investigating the historical evolution (Giannopoulou et al., 2014; Pinho and Oliveira, 2009). Such studies serve to understand or aim to find a relationship between urban form and urban policies as well as social life (Conzen, 2001) and between urban form and microclimate, thermal comfort, urban cool/heat island and energy consumption (Chatzidimitriou and Yannas, 2016; Bouyer et al. 2011).

Lastly, urban morphology has applied value. Urban design practitioners have long been trying to set the urban design guidelines to create better environments for specific sites. A large number of municipalities in developed countries publish urban design guidelines (i.e. Essex County Council, 2004; Essex Planning Officers Association, 1997). Such guidelines aim to provide suggestions about the ideal forms via discussing the relations between streets, buildings and plots. Yet, they rarely refer to quantitative urban morphology. The discussions about the relations between streets, buildings and plots are mostly intuitive and descriptive. Undeniably, such subjective explanations are not enough to guide design regulations. Systematic quantitative analyses are needed to provide more clear explanations for the implications of design options. Quantitative urban morphology can fill this gap. An important emerging trend in urban design is also parametric urbanism (Schumacher, 2012), giving a new centrality to algorithm- and rule-based generation of urban form. Once again, the challenge will be the capacity of quantitative urban morphology to serve as input and/or reference framework to parametric urbanism, in order to avoid the divergence between morphological studies and design proposals that could already be observed in more classical human-centered design praxis.

\section{Potential Implications of Urban Morphology in Environmental Psychology}

Environmental psychology focuses on the interrelation between "physical space" and human perception, cognition, preference and behaviour. Given that the rich set of indicators derived via urban morphology methods would definitely help environmental psychologist to understand, measure and classify the features of physical space which leads differences in people's perceptions and behaviour (Kubat, 2015). The issues discussed in the discipline of environmental psychology involve environmental satisfaction and preference and relatedly quality of life, image of the urban form (identity and place attachment, perceived safety, crowding, privacy, personal space) and environmental perception and cognition (wayfinding, orientation, legibility of space, physical activity, walkability) (Bechtel, 1997; 2002). For all, researchers attempt to understand what kind of urban forms are preferred, evaluated as aesthetically pleasing or legible, can decrease orientation problems, improve physical activity of inhabitants, encourage walking in the urban area etc. This would help designers to understand why people avoid some spaces and prefer to spend time in others (Nasar, 1992). Without understanding this relation between the form and the human behaviour, it is not possible to design with people in mind (Kaplan et al., 1998).

Quality of life studies investigate the formal features of residential areas via measures of transportation safety, presence and accessibility to socio-cultural entities, recreational areas, educational and health facilities (Çubukcu and Erin, 2016) all of which can be measured via geoprocessing. Specifically, space syntax, multiple centrality assessment and similar configurational network analysis models can measure accessibility such as the one used by Marshall (2005). In parallel, the characterization of urban fabrics can be measured via morphological methods such as the ones used by Urhahn and Bobic (1994), Berghauser-Pont and Haupt (2010) and, more 
recently, Araldi and Fusco (2017). Moreover, most environmental aesthetics studies attempt to measure the complexity and coherence in the spatial setting. However, they often rely on subjective measures (people's perceptions). None has used fractal analysis related to human perception, neither in micro (facades, signs) nor in macro scales (street scape, townscape), to measure complexity and coherence, despite its potential to serve as an objective measure. Studies on the image of the urban form try to define the physical features of coherent and unique urban areas which facilitate social interaction, increase perceived safety, provide enough personal space and appropriate enclosure (i.e. Stamps and Smith, 2002; Stamps, 2005). Some of these physical features (building density and building / plot / street relation) can be measured via urban fabric analyses and typology analyses.

The studies related to environmental perception and cognition investigate the physical components (i.e. number of street turns, environmental diversity, visibility of destination, building height / street width ratio) that prevents wayfinding difficulties (i.e. Evans, 1980; Carpman and Grant, 2002) and decreases perceived distances (Sadalla and Magel, 1980) encourages organic transportation modes such as walking (Cubukcu, 2013; Cubukcu, et. al., 2015a; 2015b). The model developed by Araldi and Fusco (2017) can be utilized in such studies, as it measures urban form from pedestrian point of view. Considering the fact that physical activity and walkability issues are not just related to accessibility and continuity of streets, but also to environmental perception (comfort, aesthetics and safety in routes), Araldi and Fusco's methodology is potentially applicable to studies of environmental perception and walkability. Their objective measures of environmental features from pedestrian point of view make a significant contribution for studies of environmental psychology in general and for studies of environmental perception, cognition, walkability of urban environments in specific (both of which put humans at the centre). An important research perspective for environmental psychologists is to put these "objective" measures of observable form in relation to the "subjective" measures of perceived form, paying attention to the physiological, psychological and socio-cultural factors of human perception and cognition.

The question of neighbourhood satisfaction is a good example where urban morphology analysis through geoprocessing can foster research in environmental psychology and finally produce recommendations for urban design. Neighbourhood satisfaction encompasses housing characteristics, presence of facilities and perceived elements of urban form in the neighbourhood.

Having objective measures of urban form through geoprocessing can enable making a comparison between the urban fabric characteristics observed by the analysts (here through specific geoprocessing protocols) and those perceived by city users or residents. Further analysis could then focus on the evaluation by residents of their own living environment. This evaluation is always subject to social and cultural values; specific survey schemes should thus be developed to understand people's perceptions and preferences. Possibly, ideal urban forms in terms of physical and social needs of the residents of a given neighbourhood could be identified, and these could serve as an approach to produce contextspecific urban design guidelines.

\section{Conclusion}

Urban morphology investigates "urban form". Environmental psychology, in an urban setting, is defined as the study of "the relation between urban form and human behaviour". Urban design is the process of designing villages, towns and cities to create better living environments for all. Together with the important achievements of traditional urban morphology, new quantitative geoprocessingbased methods are increasing the potential of interaction between urban morphology, urban design and environmental psychology.

The urban design guidelines set by many municipalities should refer to morphological issues to provide better prescriptions to design environments. Subjective design suggestions can be misleading. Use of quantitative urban morphology could make such suggestions more 
objective and more applicable. On a different sphere, quantitative urban morphology analysis of real-world cities could offer a guiding framework to the emerging field of parametric urbanism.

In parallel, since the 1960s environmental psychologists attempt to understand the relation between physical environment and people's thoughts and behaviour. Their findings supposed to lead the theories and practice of architecture, urban design and planning (Lang, 1987). However, environmental psychologists need accurate quantification of morphological parameters in order to control their observations for urban form. Geoprocessing in urban morphology allows this at large scales. Conversely, environmental psychology can suggest new relevant morphological parameters in the study of interaction between urban form and human behaviour.

Considering the improvements in urban morphology (recently taking the pedestrian point of view into account to analyse urban form), one cannot deny the fact that urban morphology is one of the most promising inputs for research and practice in urban design and environmental psychology. More studies are on call to investigate the objective parameters of urban forms (measured via morphological analyses from pedestrian point of view) that improve neighbourhood satisfaction and encourage walking in the neighbourhood.

\section{References}

Alexander, C. (1977) 'A pattern language: towns, buildings, construction', (Oxford University Press).

Allain, R. (2004) 'Morphologie urbaine: géographie, aménagement et architecture de la ville', (Paris, Armand Collin).

Araldi A. and Fusco G. (2017) 'Decomposing and Recomposing the City from the Pedestrian Point of View: A New Methodology for Urban Fabric Recognition and Characterization', ICCSA 2017 Proceedings (in press).

Bechtel, R. B. (1997) Environment and behavior: An introduction (Sage).

Bechtel, R. B. (2002) Environmental
Psychology (John Wiley \& Sons, Inc).

Berghauser Pont, M., Haupt, P. (2010) SPACEMATRIX, Space, Density and Urban Form, (Rotterdam, NAi Publishers).

Bernabé, A. et al. (2013) 'Classification automatique des tissus urbains par la méthode des nuées dynamiques', 31e Rencontres AUGC, (Cachan, France), (http://augc2013.ens-cachan.fr/ Data/ Articles/Contribution1150.pdf).

Borie, A. and Denieul, F. (1984) 'Methode d'analyse morphologique des tissus urbains traditionnels', UNESCO, (http://unesdoc. unesco.org/images/0006/000623/062310fb. pdf).

Borie, A., Micheloni P, Pinon P. (1980) Formes Urbaines et Sites de Méandres. Ville Recherche Diffusion (Paris).

Borie, A., Micheloni P., Pinon P. (2006) Forme et déformation des objets architecturaux et urbains (Marseille, Paranthèses).

Bouyer, J., Inard, C., Musy, M. (2011) 'Microclimatic coupling as a solution to improve building energy simulation in an urban context', Energy and Buildings, 43(7), 1549-1559.

Caniggia, G. and Maffei, G. (1979) Lettura dell'edilizia di base (Firenze, Alinea).

Castex J., Celeste P., Panerai Ph. (1980) Lecture d'une ville : Versailles (Paris, Moniteur).

Carpman, J.R. and Grant, M.A. (2002) 'Wayfinding: a broad view. Bechtel R. (ed.) Handbook of environmental psychology (2nd ed.). Wiley, New York (2002), pp. 428442.

Chatzidimitriou, A. and Yannas, S. (2016) 'Microclimate design for open spaces: Ranking urban design effects on pedestrian thermal comfort in summer', Sustainable Cities and Society, 26, 27-47.

Conzen, M. R. G. (1960) 'Alnwick, Northumberland: a study in town-plan analysis' Transactions and Papers, Institute of British Geographers 27, iii-122.

Conzen, M. P. (2001) 'The study of urban form in the United States', Urban Morphology, 5(1), 3-14.

Cubukcu, E. (2013) 'Walking for sustainable living', Procedia-Social and Behavioral Sciences, 85, 33-42.

Cubukcu, E. and Erin, I. (2016) 'Indicators of 
Quality of Life to Compare Neighborhood Units and Regional Areas: A model to collect data in Turkish cities', EnvironmentBehaviour Proceedings Journal, 1(2), 205213.

Cubukcu, E., Hepguzel, B., Onder, Z., Tumer, B. (2015a) "Active Living for Sustainable Future: A Model to Measure "Walk Scores" via Geographic Information Systems', Procedia-Social and Behavioral Sciences, 168, 229-237.

Cubukcu, E., Hepguzel, B., Tumer, B., Onder, Z. (2015b) 'Obesity, Physical Activity, Spatial Environmental Characteristics in Three Types of Residential Settings', Procedia-Social and Behavioral Sciences, 202, 382-388.

Cutini V., Petri M., Santucci A. (2004) 'From Axial Maps to Mark Point Parameter Analysis (Ma.P.P.A.)', ICCSA 2004. LNCS 3044: 1107-1116.

Essex County Council (2004) Essex Design Guide (https://www.essex. gov.uk/Environment\%20Planning/ Development-in-Essex/Documents/ecc urbanplacesupplement.pdf) accessed 25 May 2017.

Essex Planning Officers Association (1997) The Essex Design Guide for Residential and Mixed Use Areas (http://www.colchester. gov.uk/CHttpHandler.ashx?id=17579\&p=0) accessed 25 May 2017.

Evans, G. W. (1980) 'Environmental cognition' Psychological bulletin, 88(2), 259.

Figueiredo, L., Amorim, L. (2005) 'Continuity lines in the axial system', in A Van Nes (ed), 5th International Space Syntax Symposium, (TU Delft, Faculty of Architecture, Section of Urban Renewal and Management, Delft), pp. 161-174.pp. 163.

Frankhauser P. (1994) La fractalité des structures urbaines (Anthropos, Paris).

Freeman, L. (1979) 'Centrality in social networks: conceptual clarification', Social Networks 1: 215-239.

Fusco, G (2016) 'Beyond the Built-up Form / Mobility Relationship: Spatial Affordance and Lifestyles', Computer, Environment and Urban Systems, 60: 50-66.

Fusco G. and Araldi A. (2017) 'The Nine Forms of the French Riviera: Classifying Urban Fabrics from the Pedestrian Perspective' ISUF 2017 XXIV international conference: City and territory in the globalization age (in press).

Fusco G. and Tirico M., (2016) ‘Configurational Approaches to Urban Form: Empirical Test on the City of Nice (France)', Proceedings of INPUT 2016, Sept. 14th-16th 2016, (http:/www.input2016.it/conference_2016/ conference_proceedings, pp. 376-382).

Giannopoulou, M. et al. (2014) 'Using GIS to Record and Analyse Historical Urban Areas', Tema. Journal of Land Use, Mobility and Environment,4-2014: 43-47.

Gil J., Beirão J.N., Montenegro, N., Duarte J., (2012), 'On the discovery of urban typologies: data mining the many dimensions of urban form', Urban Morphology (2012) 16(1), 27-40.

Haggett P., Cliff A., Frey A. (1977), Locational Analysis in Human Geography, (2nd Ed), (Arnold. London).

Hamaina, R., Leduc, T., Moreau, G. (2014) 'A new method to characterize density adapted to coarse city model', In Popovich V et al. (eds) Information Fusion and Geographic Information System (IF AND GIS 2013), 249-263, (Springer, Berlin).

Hillier B., Hanson J. (1984) The social logic of space (Cambridge University Press).

Hillier, B. (1998) Space is the machine: A configurational Theory of Architecture (Cambridge University Press).

Hofmeister B (2004) 'The study of urban form in Germany', Urban Morphology 8:3-12.

Kaplan, R., Kaplan, S., Ryan, R. (1998) With people in mind: Design and management of everyday nature (Island Press).

Kelbaugh. D. (2002) 'Typology: an architecture of limits', Carmona, M. and Tiesdell, S. (eds.) Urban Design Reader, p.83-98, (Architectural Press, Elsevier).

Kostof, S. (1992) 'The city assembled', The City Shaped.

Kruger, M. (1977) 'An Apporach to Built Form Connectivity at an Urban Scale', unpublished $\mathrm{PhD}$ thesis, University of Cambridge, Cambridge.

Kubat A. S. (2015) 'Kentlerin Biçimsel Yapısındaki Sayısal Mantık: Space Syntax', 
Türkiye Kentsel Morfoloji Sempozyumu Bilidiriler Kitab1, p. 32-58.

Lang, J. T. (1987) 'Creating architectural theory: The role of the behavioral sciences in environmental design', p. 205, (New York: Van Nostrand Reinhold).

Larkham, P.J. and Morton, N. (2011) 'Drawing lines on maps: morphological regions and planning practices', Urban Morphology 15:133-151.

Long, N. and Kergomard, C. (2005) 'Classification morphologique du tissu urbain pour des applications climatologiques. Le cas de Marseille'. Revue Internationale de Géomatique, 15(14), 487-512.

Madanipour, A. (1997) 'Ambiguities of urban design', Carmona, M. and Tiesdell, S. (eds.) Urban Design Reader, p.12-23, (Architectural Press, Elsevier).

Magel, S. G. and Sadalla, E. K. (1980) 'The Perception of Traversed Distance', Environment and Behavior, 12(1), 65-79.

Marshall, S. and Caliskan, O. (2011) 'A joint framework for urban morphology and design'. Built Environment, 37(4), 409-426.

Marshall, S., (2005) Streets and patterns: the structure of urban geometry (Routledge, London).

Martin L, March L, Echenique M (1972) Urban Spaces and Structures (Cambridge University Press, Cambridge).

Martin. L (1972) 'The Grid as Generator', Carmona, M. and Tiesdell, S. (eds.) Urban Design Reader p.70-82 (Architectural Press, Elsevier).

McCormack, A. (2013) 'Informing and forming practice: the imperative of urban morphology', Urban Morphology 17, 45-8.

Moudon, A. V. (2013) 'A Catholic approach to organizing what urban designers should know', Larice and Macdonald (eds.) The Urban Design Reader (2nd ed.) pp.235-257 (Routledge).

Muratori, S. (1959) Studi per una operante storia di Venezia (Rome, Istituto Poligrafico dello Stato).

Nasar, J. L. (1992) Environmental aesthetics: Theory, research, and application (Cambridge University Press).

Oliveira, V. (2013) 'Morpho: a methodology for assessing urban form', Urban Morphology, 17(1), 21-33.

Oliveira, V., Monteiro, C., Partanen, J. (2015) 'A comparative study of urban form', Urban Morphology, 19(1), 73-92.

Pinho, P. and Oliveira V. (2009) 'Cartographic analysis in urban morphology', Environment and Planning B: Planning and Design 2009, volume 36, pages 107-127.

Porta S., Crucitti P., Latora V. (2006a) 'The network analysis of urban streets: a primal approach', Environment and Planning B: Planning and Design 33(5):705-725.

Porta S., Crucitti P., Latora V. (2006b) 'The network analysis of urban streets: A dual approach', Physica A 369: 853-866.

Puissant, A. et al. (2010) 'Classification des tissus urbains à partir de données vectorielles - Application à Strasbourg', SAGEO 2010 Proceedings, Toulouse, 198-211.

Schumacher P. (2012) 'The Autopoiesis of Architecture, Volume II A New Agenda for Architecture', (John Wiley \& Sons, Hoboken).

Sevtsuk A. and Mekonnen M. (2012) 'Urban Network Analysis Toolbox', International Journal of Geomatics and Spatial Analysis, 2, 22: pp. 287-305.

Stamps III, A. E. (2005) 'Enclosure and safety in urbanscapes', Environment and Behavior, 37(1), 102-133.

Stamps III, A. E. and Smith, S. (2002) 'Environmental enclosure in urban settings', Environment and Behavior, 34(6), 781-794.

Steadman P (1983) Architectural Morphology: An Introduction to the Geometry of Building Plans (Pion, London).

Thomas, I. et al. (2007) 'Fractal dimension versus density of built-up surfaces in the periphery of Brussels', Papers in Regional Science, 86: 287-308.

Trancik, R. (1986) 'What is lost space?', Carmona, M. and Tiesdell, S. (eds.) Urban Design Reader, p.63-69, Architectural Press, Elsevier.

Turner, A. (2000) 'Angular analysis: a method for the quantification of space', Working Paper 23, (London: Centre for Advanced Spatial Analysis, UCL).

Urhahn, G. and Bobic, M. (1994) A pattern image: a typological tool for quality in urban planning (Thoth, Bussum). 
Whitehand, J. W. R. (2005) 'Urban morphology, urban landscape management and fringe belts', Urban Design, 93(1), 19-21.

Whitehand J. (2009) 'The structure of urban landscapes: strengthening research and practice', Urban Morphology 13:5-27. 